\title{
EXPERIMENTAL ASSESSMENT OF STRENGTHENING STRATEGIES AGAINST THE OUT-OF-PLANE COLLAPSE OF MASONRY INFILLS IN EXISTING RC STRUCTURES
}

\author{
Maria Teresa De Risi ${ }^{1}{ }^{(*)}$, André Furtado², Hugo Rodrigues ${ }^{3}$, José Melo², Gerardo \\ Mario Verderame ${ }^{1}$, António Arêde ${ }^{2}$, Humberto Varum ${ }^{2}$, Gaetano Manfredi ${ }^{1}$ \\ ${ }^{1}$ Department of Structures for Engineering and Architecture, University of Naples Federico II, via \\ Claudio 21, 80125, Naples, Italy, e-mail: \{mariateresa.derisi, verderam, gamanfre\}@unina.it \\ ${ }^{2}$ CONSTRUCT-LESE, Faculdade de Engenharia da Universidade do Porto, Porto, Portugal, e-mail: \\ \{afurtado, josemelo, aarede, hvarum\}@fe.up.pt \\ ${ }^{3}$ RISCO - ESTG, Polytechnic Institute of Leiria, Leiria, Portugal, e-mail: hugo.f.rodrigues@ipleiria.pt \\ ${ }^{(*)}$ beneficiary of an AXA Research Fund grant
}

\begin{abstract}
Past and more recent seismic events worldwide clearly showed that a crucial issue for lifesafety and loss reduction due to earthquakes for existing reinforced concrete $(R C)$ buildings is related to the out-of-plane (OOP) collapse of infill masonry walls. In literature, few studies addressed this paramount topic, above all about the proposal of strengthening strategies to prevent the infills' collapse. This paper presents an experimental work about the assessment of possible strengthening solutions designed to mitigate or prevent the out-of-plane collapse of masonry infills in existing RC buildings. Three nominally identical full-scale one-bay-one-story $R C$ frames were built and infilled with a thin masonry wall made up of horizontal hollow clay bricks. The first specimen was representative of the enclosure of a typical existing RC building in the Mediterranean region in its "as-built" condition. The remaining two specimens were strengthened against the out-of-plane collapse by means of two different strengthening techniques based on the application of innovative systems made up of high-ductility mortar plaster and fibre-reinforced polymer nets. All the tests consisted in the application of a semi-cyclic (loading-unloading-reloading) history of imposed displacements in the OOP direction by means of small pneumatic jacks through a uniform distributed load. Experimental results are shown in terms of OOP force-displacement responses, deformed shapes and damage evolution. In the end, the results of the tests are compared to assess the effectiveness of the selected strengthening techniques and to provide a support towards the choice of the best strategies for future further investigations and applications.
\end{abstract}

Keywords: RC buildings, masonry infills, out-of-plane collapse, strengthening strategies, experimental tests. 


\section{INTRODUCTION}

Seismic events worldwide clearly showed that a crucial issue for life-safety and loss reduction due to earthquakes for existing reinforced concrete (RC) buildings is related to the out-ofplane (OOP) collapse of infill masonry walls. In the last thirty years, a quite limited number of experimental tests was presented in the literature on unreinforced masonry infills in RC frames under OOP loading (e.g., [1]-[4]). Even less studies addressed the paramount topic of the strengthening strategies to prevent the infills' OOP collapse. The latter point is still a frontier issue for the most recent research works and it represents the focus of the present paper.

The integration of the infill panels on the substructure and respective improvement of the OOP collapse vulnerability can be achieved by using different techniques, such as: fiber reinforced polymers (FRP), engineered cementitious composites, textile reinforced mortars (TRM) or bed joints reinforcement. Experimental studies can be found in the literature concerning this topic by means of the realization of mechanical characterization tests on small panels or OOP tests in infill panels embedded in RC frames.

Regarding the TRM technique, Guidi et al. [5] carried out combined IP-OOP tests with the aim of characterizing the OOP behaviour of infill walls made with different types of masonry units, with and without reinforcement. The authors tested four specimens (two as-built and two strengthened) and the strengthening strategy consisted on the application of a special quadriaxial net made with hybrid glass fibers, that was casted in an extra fiber-reinforced plaster layer. From the test results, the authors concluded that strengthened specimens reached $30 \%$ higher OOP strength, due to the development of an arch mechanism, even for higher values of previous IP drift. Later, Koutas et al. [6] studied the development and performance of new textile-based anchors. Two different textiles were used as externally bonded reinforcement of the specimens: (i) a commercial textile with equal quantity of epoxy-coated glass fibers in two orthogonal directions; and (ii) lighter commercial textile (with a larger mesh size) made of elastomeric polymer-coated E-glass with equal quantity of fibers in two orthogonal directions. From the tests, the authors pointed that the increment of the fibers quantity in the anchors resulted in a nonproportional increase of the forces carried by them. The anchors placed between two layers of textiles were more effective, about $50 \%$, than the ones placed on top of a single layer. Da Porto et al. [7] assessed the effectiveness of different plasters and TRM to retrofit infill panels made with hollow clay horizontal bricks subjected to combined IP-OOP tests. Different solutions were tested, namely: i) special lime-based plaster with geo-polymer binder; ii) bidirectional composite meshes with inorganic matrices (TRM); iii) TRM improved by anchorage of the mesh to the RC frame. From the results, the authors pointed out that the OOP behaviour of 'light' clay damaged panels after IP test clearly improved with plasters made of natural hydraulic lime, with or without geopolymer binder, reaching around 2.7 times higher OOP strength. The anchorages embedded in the TRM fixed to the upper beam did not change significantly the panel OOP capacity. The authors also pointed out the reduction of the displacement at the maximum strength and allowed reaching a controlled failure mode. Martins et al. [8] tested an innovative strengthening technique based on TRM technique with meshes based on composite rod composed by an external polyester protection. The idea of the authors was that the core provides the reinforcement and the external polyester braided rod contribute with the residual strength and deformation capacity which controls the damage and avoids brittle failure of the masonry units. Flexural strength tests perpendicular to the horizontal bed joints were carried out and the results indicated that the flexural cracking load increased between $7 \%$ to $34 \%$ for manufactured mesh with glass and carbon fibers, respectively. The authors also found that cracked stiffness was about $50 \%$ and $10 \%$ of the initial stiffness in the case of meshes made 
with carbon fiber and glass fiber, respectively. The bending strength was higher in the specimens strengthened with the manufactured meshes comparatively with the equivalent commercial meshes.

All the studies herein presented revealed interesting results in terms of increase of the deformation capacity of the panels and prevention of brittle failures. From, a technical point of view all of the techniques are effective if the retrofit material is well anchored to the surrounding frame and bonded to the panel. Different types of anchors were found in the literature, with different materials, with different application procedures, etc., but without proper design and application of the anchors, the strengthening strategy may not be effective.

This paper presents an experimental work performed in the Laboratory of Earthquake and Structural Engineering of the Civil Engineering Department of the University of Porto in cooperation with the Department of Structures for Engineering and Architecture of the University of Naples Federico II. The experimental tests presented herein are about the assessment of possible strengthening solutions designed to mitigate and prevent the OOP collapse of masonry infills in existing $\mathrm{RC}$ buildings.

Three nominally identical full-scale one-bay-one-story RC frames were built and infilled with a thin masonry wall made up of horizontal hollow clay bricks. The first specimen was representative of the enclosure of a typical existing $\mathrm{RC}$ building in the Mediterranean region in its "as-built" condition. The remaining two specimens were strengthened to reduce the out-ofplane collapse vulnerability by means of two different strengthening techniques based on the application of innovative systems made up of high-ductility mortar plaster and fibre-reinforced polymer nets. All the tests consisted in the application of a semi-cyclic (loading-unloadingreloading) history of imposed displacements in the OOP direction by means of small pneumatic jacks through a uniform distributed load. The mechanical properties of the adopted materials have been characterized and presented. The paper presents the experimental results analysed in detail in terms of OOP force-displacement responses, deformed shapes and damage evolution.

In the end, the results of the tests are compared to assess the effectiveness of the selected strengthening techniques and to provide a support towards the choice of the best strategies for future further investigations and applications.

\section{EXPERIMENTAL TEST PROGRAM}

Three nominally identical full-scale one-bay-one-story RC frames were built and infilled with a thin masonry wall made up of horizontal hollow clay bricks. The first specimen was representative of the enclosure of a typical existing RC building in its "as-built" condition. On the other two identical specimens, two different strengthening techniques were applied to prevent the out-of-plane collapse, both based on the application of high-ductility mortar plaster and fibre-reinforced polymer nets, as described in Section 2.1. Materials properties, instrumentation and setup adopted for these tests are briefly described in Sections 2.1 and 2.2.

\subsection{Specimens descriptions}

The testing campaign presented herein comprised three nominally identical full-scale, onebay-one-story RC frames infilled with a thin masonry wall made up of horizontal hollow clay units. The infill panels' geometric dimensions were defined as $4.20 \times 2.30 \mathrm{~m}$ (length and width respectively). The columns' and beams' cross sections were $0.30 \mathrm{x} 0.30 \mathrm{~m}$ and $0.30 \mathrm{x} 0.50 \mathrm{~m}$, respectively. Figure 2 shows the schematic layout of the specimen geometry. All the infill panels have equal geometry with the above-mentioned dimensions, made of $(300 \times 200 \times 100) \mathrm{mm}$ hollow clay horizontal bricks (with 110mm thickness), as shown in Figure 1. 


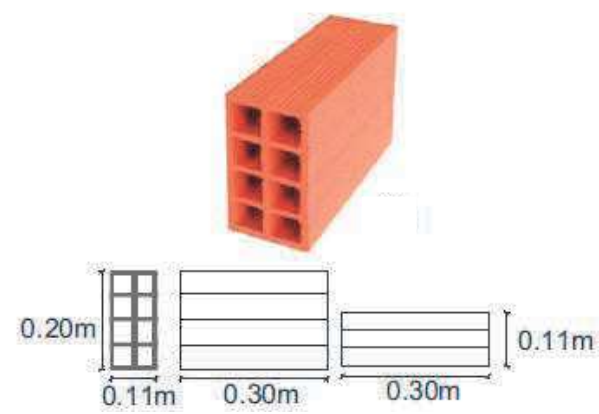

Figure 1: Adopted brick typology - adapted from [1].

No reinforcement was used to connect the infill panel and the surrounding RC frame, and no gaps were adopted between the panel and the frame. A traditional mortar M5 class was considered a suitable choice for the construction of the panels. The testing campaign is composed by the as-built specimen (herein designated "AB-OOP") and two retrofitted specimens (R1-OOP and $\mathrm{R} 2-\mathrm{OOP}$ respectively).

Concerning to the RC frame material properties, a C20/25 concrete was assumed and steel reinforcement A500 class were used (with a nominal mean yielding stress equal to $500 \mathrm{MPa}$ ).

In the next sub-sections, the strengthening solutions adopted for each strengthened specimen (panels R1-OOP and R2-OOP) will be described. Table 1 reports a summary of the three specimens tested and analysed in the following sections.

\begin{tabular}{lll}
\hline Specimen ID & G-FRP net on the infill & Connection to the frame \\
AB-OOP & No & No \\
R1-OOP & Yes & No (Plastic connectors) \\
R2-OOP & Yes & Yes (L-shape bars connectors) \\
\hline
\end{tabular}

Table 1: Experimental tests.

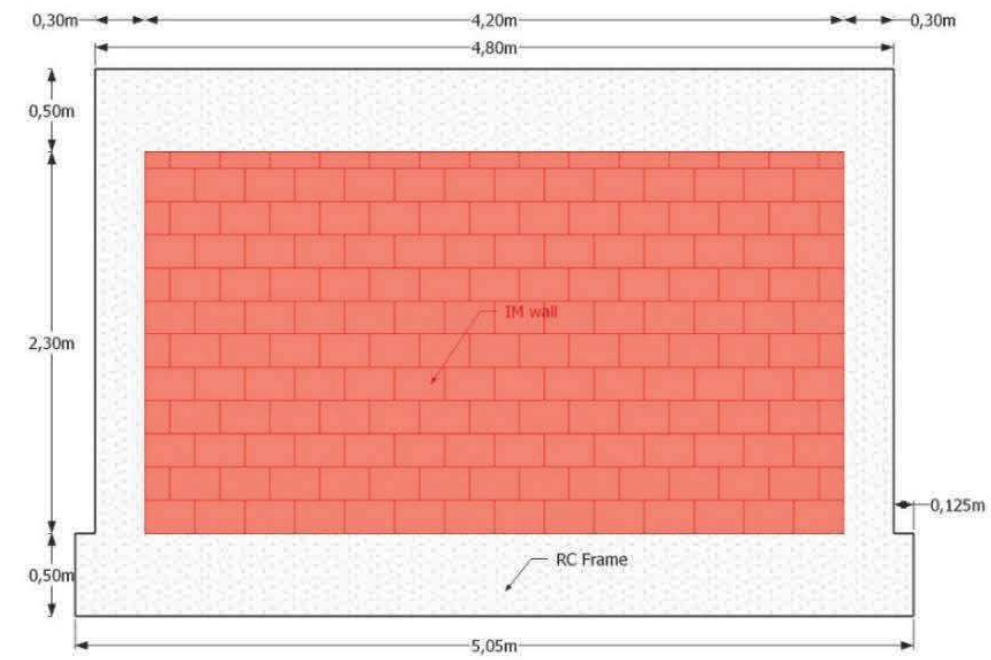

Figure 2: Infilled RC frame specimen general dimensions (units in meters).

\subsubsection{Specimen R1-OOP}

The strengthening solution adopted for the specimen R1-OOP was a textile reinforced mortar composed by a glass-fibre net designated "FASSANET ARG 40" commercialized by FASSA BORTOLO, with a matrix $4 \times 4 \mathrm{~cm}$, a tensile strength equal to $56.25 \mathrm{kN} / \mathrm{m}$ and a maximum ultimate strain equal to $3 \%$. 
The mortar used for the plaster was a ductile one, designated "SISMA" and commercialized also by FASSA BORTOLO. The mean compression and tensile strengths of the plaster mortar at the day of the test were around $24.4 \mathrm{MPa}$ and $6.7 \mathrm{MPa}$, respectively. The net was positioned and fixed to the RC frame and to panel by means of plastic connectors. Thus, the application procedure of this strengthening strategy started by the application of $1 \mathrm{~cm}$ plaster. Then the net was positioned and fixed with the plastic connectors. The roll of net was provided with 1 meter width and 50 meters length. Five vertical strips were used to strengthen the wall, as can be observed in Figure 3. The overlap length used between each vertical strip were assumed to be $10 \mathrm{~cm}$, and for the transition RC frame-infill panel it was assumed a duplicate net with an overlap equal to $30 \mathrm{~cm}(15 \mathrm{~cm}$ for the $\mathrm{RC}$ frame and $15 \mathrm{~cm}$ for the infill panel). The disposition and distribution of the connectors is shown in Figure 3a, and the general view of the specimen R1OOP is shown in Figure 3b. At the end, an additional $1 \mathrm{~cm}$ layer of ductile mortar was applied, so that the final thickness of the retrofitting plaster was equal to $2 \mathrm{~cm}$.

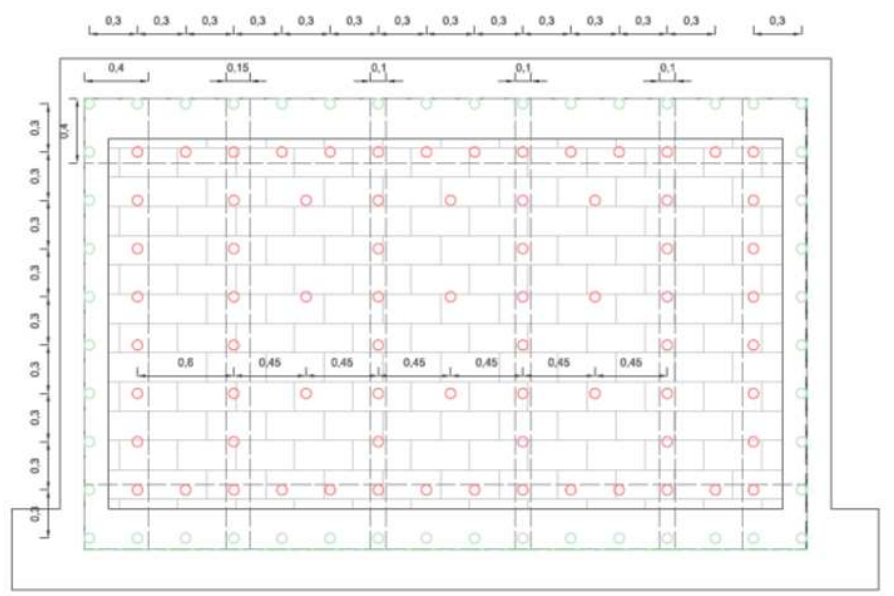

(a)

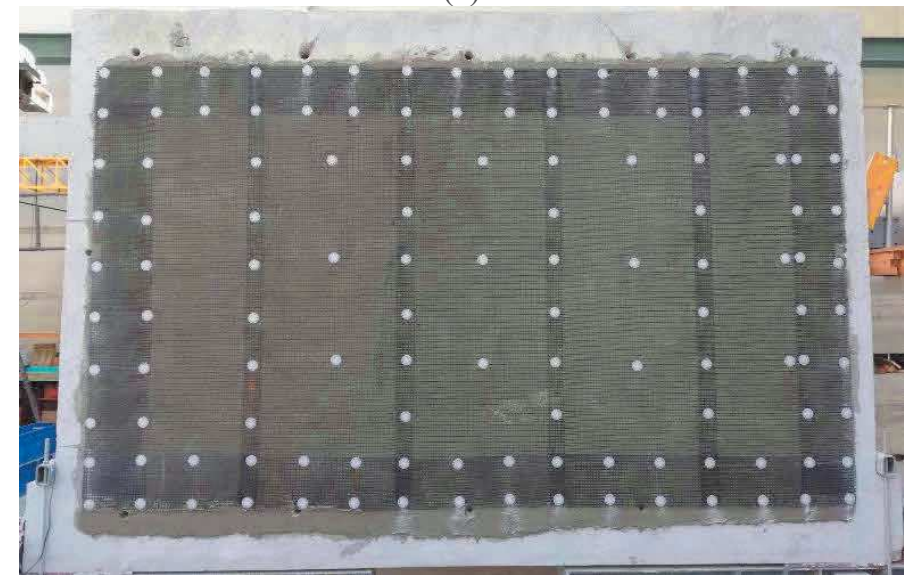

(b)

Figure 3: Specimen R1-OOP: (a) strengthening schematic layout and (b) general view.

\subsubsection{Specimen R2-OOP}

The strengthening solution selected for specimen R2-OOP was similar to the one adopted for specimen R1-OOP. The difference among them was related to the anchorage of the net to the frame. In this case, L-shape connectors were used to fix the net to the RC frame (Figure 4).

The application procedure adopted to apply this connectors was: 1) application of the first layer of plaster with thickness equal to $1 \mathrm{~cm} ; 2$ ) application of the net; 3) drilling a hole with $\phi 6 \mathrm{~mm}$ diameter and $10 \mathrm{~cm}$ length for each connector; 4) full filling of the hole with epoxy resin 
(provided by the manufacturer); 5) application of the L-shape connector; and 6) application of the second layer of $1 \mathrm{~cm}$ plaster. The net and the plaster were the same used in the specimen R1-OOP.

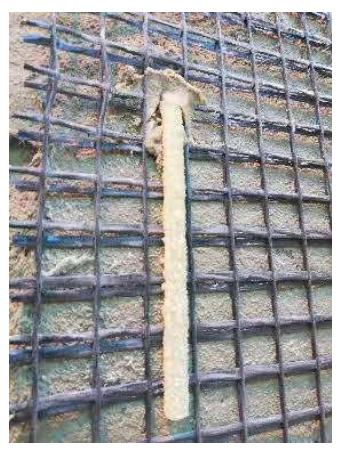

Figure 4: Specimen R2-OOP: Detail of the L-shape connector.

\subsection{Test Setup, instrumentation and loading protocol}

The OOP test setup consists in the application of a distributed OOP loading through 28 pneumatic actuators that mobilized the entire infill panel surface resorting to wood plates with dimensions $0.5 \times 0.5 \mathrm{~m}^{2}$ placed between the actuators and the panel. The pneumatic actuators were linked to four horizontal alignments performed by HEB140 steel shapes which reacted against five vertical alignments performed by HEB200 steel shapes. The horizontal alignments were coupled with hinged devices that allow lateral sliding. This steel reaction structure is a self-equilibrated structure designed with a concept similar to the previous experimental campaigns carried out by Furtado et al. ([1]-[2]). The steel structure is attached to the RC frame in twelve points (5 in the bottom and 5 in the top beam and 2 in middle-height columns) with steel bars that are coupled with load cells that allow monitoring the OOP loadings. Figure 5a and Figure $5 \mathrm{~b}$ shows the schematic layout and the general view of the test setup.

Concerning to the instrumentation assumed for all the tests (Figure 5c), 34 displacement transducers were used to measure the OOP displacements of the panel, OOP displacements of the frame, relative displacements between the panel and the frame and vertical displacement of the top beam.

Lastly, the loading protocol consisted on the application half-cyclic OOP displacements (loading-unloading) that were imposed with steadily increasing displacement levels, targeting the following nominal peak displacements: $0.5,1,1.5,2,2.5,3.5 ; 5 ; 7.5 ; 10 \mathrm{~mm}$; and so on 5 by $5 \mathrm{~mm}$ until a maximum OOP displacement of $120 \mathrm{~mm}$. Two half-cycles were repeated for each lateral deformation demand level at the control node to evaluate the strength degradation.

\section{EXPERIMENTAL RESULTS}

In this Section, the results of the experimental testing procedure described above are presented and analysed test by test. OOP load (FoOP) versus OOP displacement in the centre of the infill panel (doop,center) responses are shown, together with the deformed shapes along given vertical alignments and damage evolution from the first observed cracks on the panel to the end of the test. 


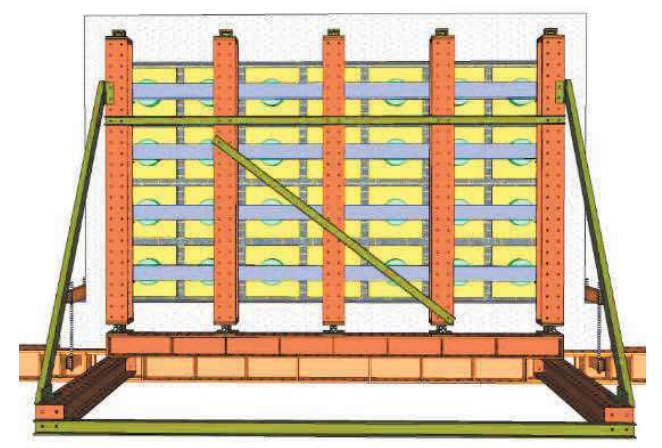

(a)

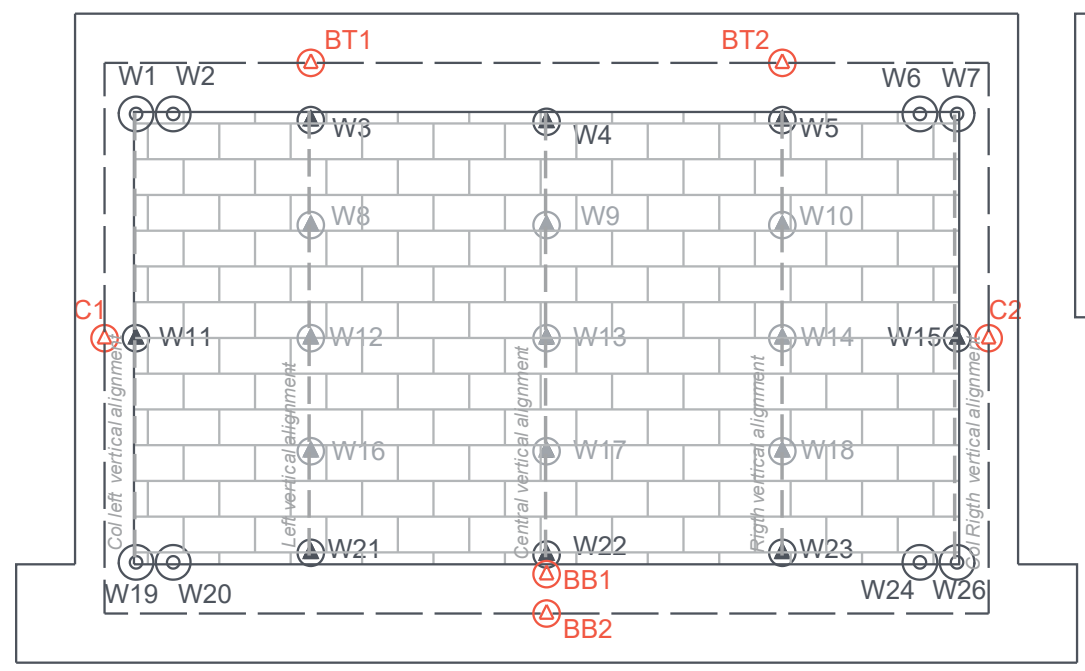

(c)

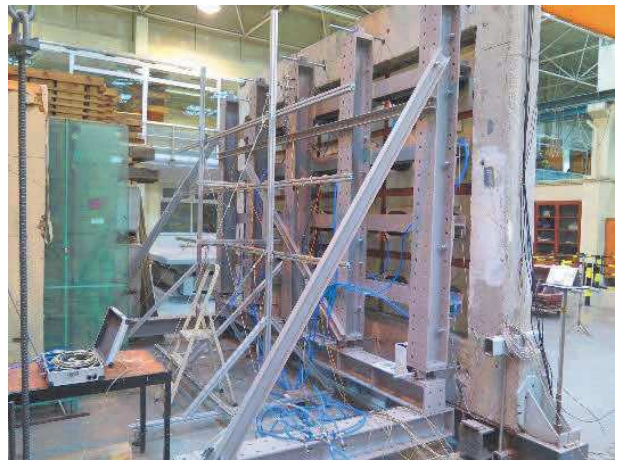

(b)
Legend:

(4) LVDT OOP masonry infill wall displacement

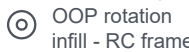

(4) OOP RC frame displacement

(4) wire OOP masonry infill wall displacement

Figure 5: Experimental campaign: (a) test setup schematic layout, (b) test setup general view, and (c) instrumentation.

\subsection{Specimen AB-OOP}

Figure 6 shows the semi-cyclic OOP force-displacement response for the as-built specimen (AB-OOP) and the deformed shape of the panel along three vertical alignments (as shown in Figure 5c) at the peak load condition. First, note that the OOP displacement used in Figure 6a (and in the similar ones in the following analyses) is the displacement monitored by the displacement transducer located in the geometrical centre of the panel (W13 in Figure 5c).

The initial (secant) stiffness of this response - calculated as the ratio between Foop and doop,centre at the first peak related to the first applied displacement level - is equal to kOOP,sec,in $=8.89 \mathrm{kN} / \mathrm{mm}$. By increasing the applied OOP displacement, a first visible (macro-) cracking was observed on the panel for an applied OOP displacement in the centre equal to $2.5 \mathrm{~mm}$, at Foop,,$=21.81 \mathrm{kN}$ (see Figure $6 \mathrm{a}$ ). At this stage, a horizontal crack along a mortar bed joint occurred in the middle of the panel, as shown in Figure 7a. The secant stiffness related to this first cracking is thus slightly lower than the initial one, and in particular equal to $8.72 \mathrm{kN} / \mathrm{mm}$. Secant stiffness progressively reduced during the test, and progressively wider cracks appeared in the panel, drawing on it a quite clear "pavilion" shape until the peak load is reached (see Figure $6 \mathrm{~b}$ and Figure $7 \mathrm{~b}$ ). The pavilion-deformed shape highlights the existence of a double-arch (horizontal and vertical) resisting mechanism, as expected for an infill panel connected with the surrounding frame along four-edges [3]. The maximum OOP load corresponding to this stage was equal to Foop, $\max =52.68 \mathrm{kN}$ at doop, centre, $\max =39.55 \mathrm{~mm}$. The corresponding secant stiffness thus reduced to $1.33 \mathrm{kN} / \mathrm{mm}$. At about $45 \mathrm{~mm}$ of applied OOP 
displacement, the infill panel totally collapsed out of its plane, after its detachment from the top beam, and the crushing of the hollow clay bricks in the compressed portions of the panel (see Figure $7 \mathrm{c})$.

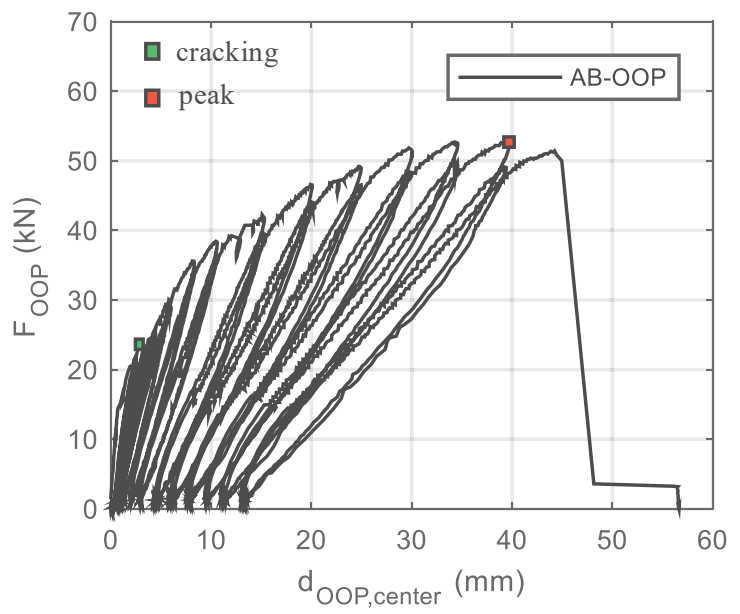

(a)

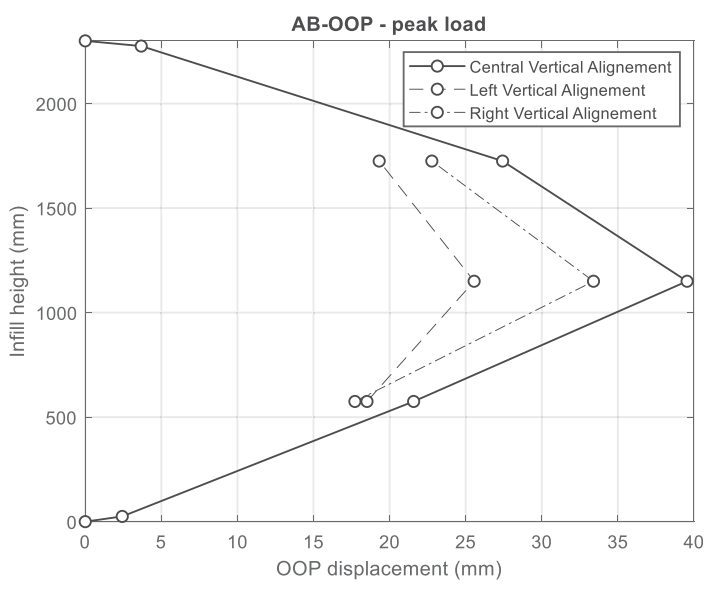

(b)

Figure 6: Test AB-OOP - $\mathrm{F}_{\mathrm{OOP}}-\mathrm{d}_{\mathrm{OOP}}$ response (a) and deformed shape along vertical alignments at $\mathrm{F}_{\mathrm{OOP} \text {,max }}(\mathrm{b})$.

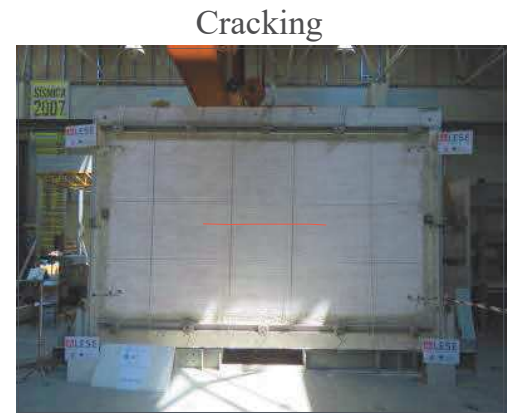

(a)

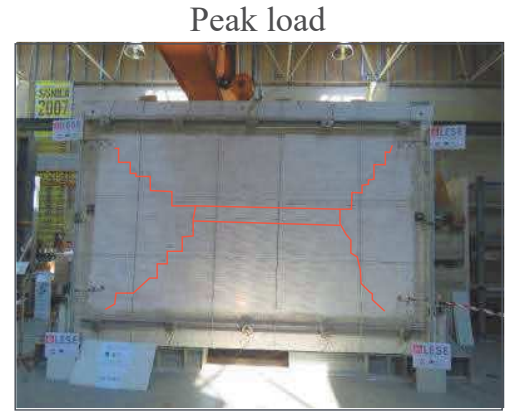

(b)

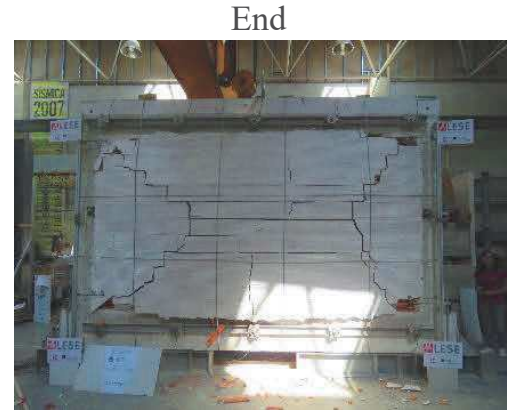

(c)

Figure 7: Test AB-OOP cracking pattern- First cracking (a); peak load (b); end of the test (c).

\subsection{Specimen R1-OOP}

Figure 8 shows the OOP force-displacement response for the first retrofitted specimen (R1OOP) and the deformed shape of the panel along five vertical alignments (see Figure $5 \mathrm{c}$ ) at the peak load.

For this test, the initial (secant) stiffness of the response - calculated as explained before is equal to $\mathrm{koOP}, \mathrm{sec}, \mathrm{in}=29.15 \mathrm{kN} / \mathrm{mm}$, namely significantly higher $(+228 \%)$ than the koop,sec,in related to the specimen AB-OOP. Such a difference is mainly ascribable to the presence of the plaster for the specimen R1-OOP. By increasing the applied OOP displacement, first visible (macro-) cracks were observed on the panel for an applied OOP displacement in the centre equal to $3.6 \mathrm{~mm}$, at Foop,cr $=70.47 \mathrm{kN}$ (see Figure $8 \mathrm{a}$ ). At this stage, hairline horizontal and vertical cracks appeared in the middle of the panel, as shown in Figure 9a. The secant stiffness related to this first cracking thus reduced to $19.58 \mathrm{kN} / \mathrm{mm}$. Secant stiffness progressively reduced during the test, and progressively wider cracks appeared in the panel, with additional diagonal cracks in the bottom portion of the panel, until the peak load was reached (Figure 9b). The maximum OOP load corresponding to this stage was equal to $F_{O O P, \max }=95.95 \mathrm{kN}$ at doop,centre,max $=15.00 \mathrm{~mm}$. At peak load, a significant detachment from the top beam was measured, as 
shown in Figure $8 \mathrm{~b}$. From the achievement of the peak load to the end of the test, there were the progressive widening of the central cracks, the detachment of the reinforcing plaster for the top part of the frame, and a pronounced slippage of the plastic connectors from the top beam and from the lateral columns (see Figure 9c).

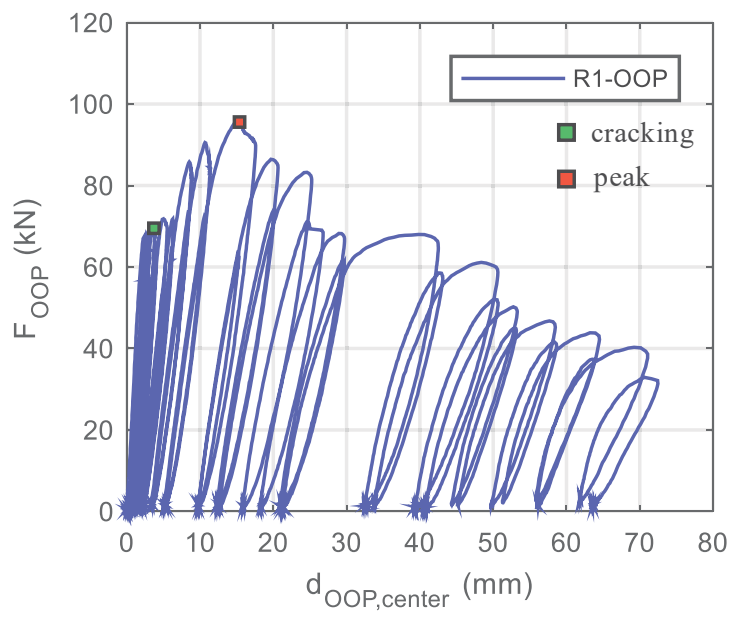

(a)

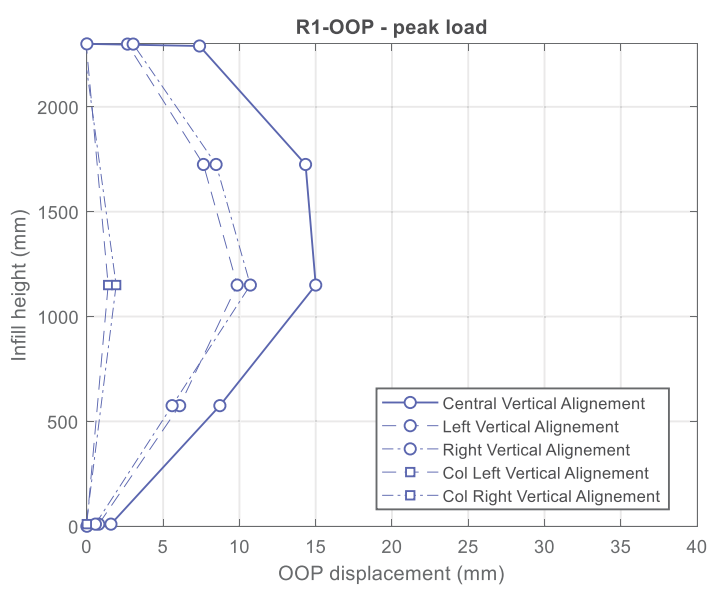

(b)

Figure 8: Test R1-OOP - FOOP-dOOP response (a) and deformed shape along vertical alignments at FOOP,max (b).

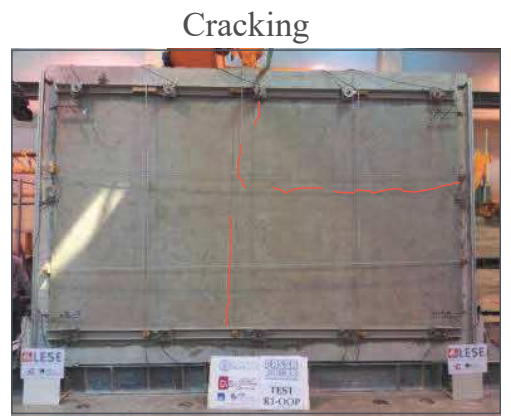

(a)

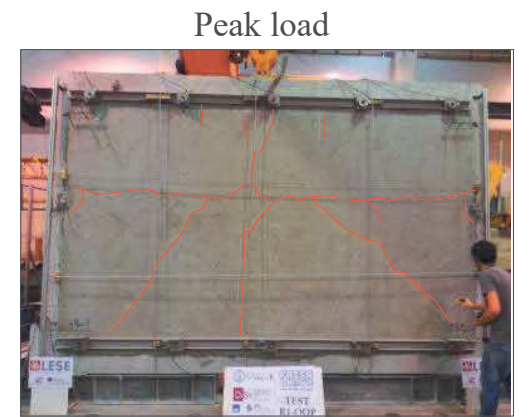

(b)

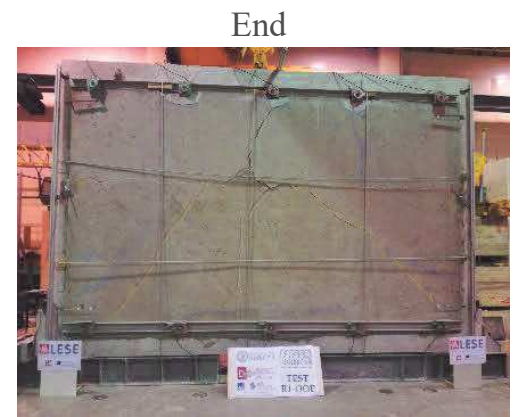

(c)

Figure 9: Test R1-OOP cracking pattern - First cracking (a); peak load (b); end of the test (c).

\subsection{Specimen R2-OOP}

Figure 10 shows the OOP force-displacement response for the retrofitted specimen R2-OOP and the corresponding deformed shape at the peak load, as for the previous tests. For this test, the initial secant stiffness - calculated as explained before - is equal to koop, sec,in $=34.85 \mathrm{kN} / \mathrm{mm}$, namely slightly higher than the kooP,sec,in related to specimen R1-OOP, likely due to the stronger degree of connection between the retrofitting plaster on the panel and the frame. For increasing applied OOP displacement, a first visible (macro)-cracking was observed on the panel, at Foop,cr $=89.73 \mathrm{kN}$ and doop,center equal to about $3 \mathrm{~mm}$ (see Figure 10a). At this stage, a hairline horizontal crack appeared in the middle of the panel together with some smaller vertical cracks on the bottom, as shown in Figure 11a.

Secant stiffness progressively reduced, and progressively wider cracks appeared in the panel, with additional diagonal cracks in the bottom portion of the panel, vertical central cracks and horizontal cracks at the infill-top beam interface, until the peak load was reached (Figure 11b). The maximum OOP load corresponding to this stage was equal to $F_{0 O P, \max }=116.70 \mathrm{kN}$ at doop,centre, $\max =15.34 \mathrm{~mm}$. The above-mentioned horizontal cracks at the infill-top beam interface 
highlighted the increasing OOP sliding of central bricks on the top of the panel (visible on the backside of the wall and measured by the top LVDTs, as shown in Figure 10b) involving "monolithically" bricks and retrofitting plaster.

From the achievement of the peak load to the end of the test, there were the progressive widening of the central cracks, the crushing of some clay bricks in the bottom and a slight OOP sliding along the infill-bottom beam interface. The damage state at the end of this test, at doop,centre practically equal to the infill wall thickness, is shown in Figure 11c. It is worth noting that, at the end of the test, the system "infill panel + retrofitting plaster" detached from the upper part, but it still remained connected along the columns and to the bottom part of the frame. In the top of the panel where the sliding was observed, at the end of the test, the connectors were still in-situ, but the glass fibre net was locally cut around the connectors.

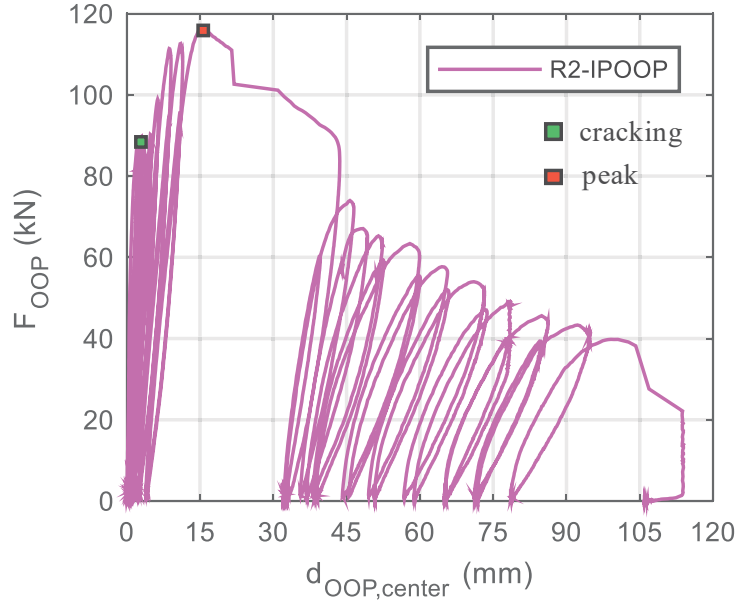

(a)

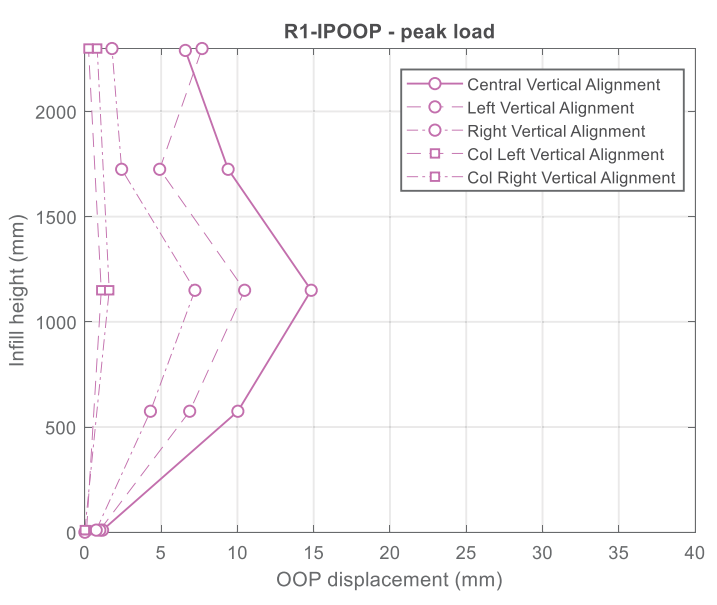

(b)

Figure 10: Test R2-OOP - FOOP-dOOP response (a) and deformed shape along vertical alignments at FoOP,max (b).

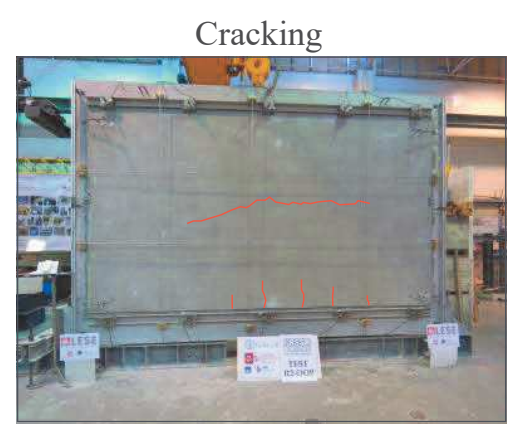

(a)

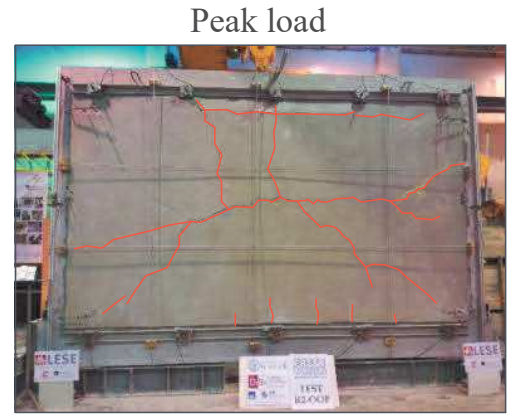

(b)

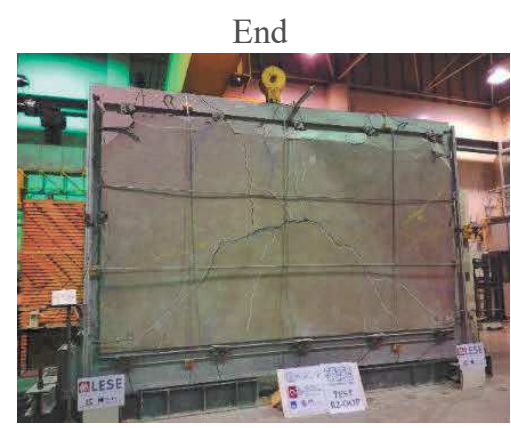

(c)

Figure 11: Test AB-OOP cracking pattern - First cracking (a); peak load (b); end of the test (c).

\section{COMPARISONS OF THE RESULTS}

Figure 12 shows a comparison among the test results presented in the previous section, in terms of Foop-doop,center envelope (Figure 12a) and of secant stiffness $\left(\mathrm{k}_{\mathrm{sec}}\right)$ evolution (Figure 12b). Please, note that envelopes in Figure 12a are shown until the last first-cycle peak. Additionally, Table 2 provides a summary of the results commented above.

It can be noted that the maximum FOOP for the retrofitted specimens are 1.82 and 2.22 times the FoOP,max related to the AB-OOP specimens, for tests R1-OOP and R2-OOP, respectively. This aspect can be particularly important for typical code-based safety checks for the out-of- 
plane collapse of masonry infills, since they are generally carried out in terms of strength (e.g. [9], [10]).

Significant force increment are observed at the first (macro-) cracking condition: Foop,cr is 3.23 and 4.11 times the related value for the AB-OOP specimen, for tests R1-OOP and R2OOP, respectively. Secant stiffness is also significantly affected by the presence of the retrofitting plaster, by increasing of at least of $+228 \%$ with respect to AB-OOP specimen.

On the contrary, the OOP displacement at the peak OOP load (dooP,center,max) is about the $40 \%$ of the related displacement of AB-OOP specimen for both the retrofitted tests. The displacements corresponding to $20 \%$ of strength reduction (namely, corresponding to the $80 \%$ of the maximum load) on the envelopes (doop,center,u,80\%) are also reported in Table 2 . The corresponding deformation capacity, calculated as the ratio between doop,center,u, $80 \%$ and doop,center,max, are $53 \%$ and $43 \%$ higher than the reference specimens AB-OOP, for specimens R1-OOP and R2OOP, respectively.

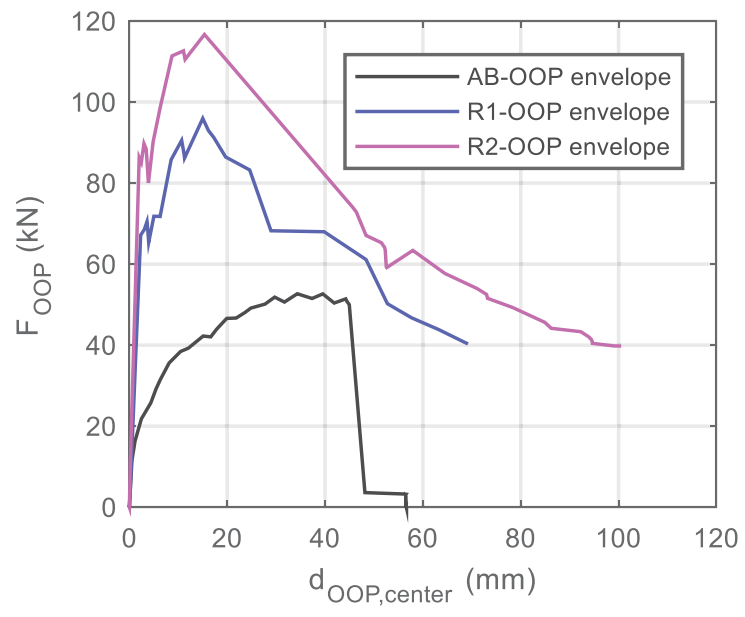

(a)

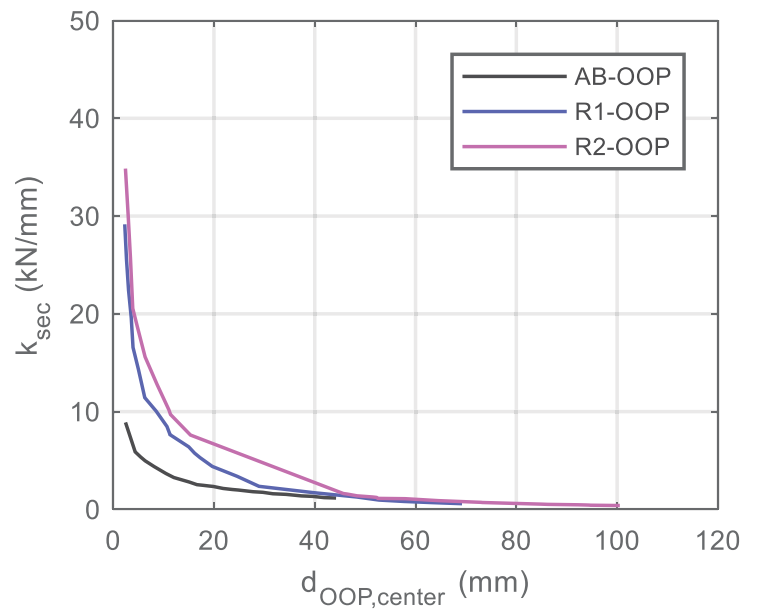

(b)

Figure 12: Comparison of the results - FOOP-dOOP envelopes (a) and secant stiffness evolutions (b).

\begin{tabular}{llllll}
\hline & AB-OOP & R1-OOP & R2-OOP & R1/AB & R2/AB \\
\hline FOOP,max $(\mathrm{kN})$ & 52.68 & 95.95 & 116.70 & 1.82 & 2.22 \\
FOOP,cr $(\mathrm{kN})$ & 21.81 & 70.47 & 89.73 & 3.23 & 4.11 \\
kOOP,sec,in $(\mathrm{kN} / \mathrm{mm})$ & 8.89 & 29.15 & 34.85 & 3.28 & 3.92 \\
doOP,center,max $(\mathrm{mm})$ & 39.55 & 15.00 & 15.34 & 0.38 & 0.39 \\
doOP,center,u,80\% (mm) & 45.46 & 26.47 & 25.32 & 0.58 & 0.56 \\
$\mu_{\text {OOP,center,u,80\% (-) }}$ & 1.15 & 1.76 & 1.65 & 1.53 & 1.43 \\
\hline
\end{tabular}

Table 2: Comparisons of the results.

An additional interesting comparison among the presented test results can be carried out in terms of observed "failure mode", described in the previous sub-sections. Certainly, the most critical point of this kind of retrofitting strategy is the connection between the system "ductile mortar plaster + fibre-net" and the surrounding frame. An effective connection is necessary to prevent a premature physical collapse of the panel out of its plane. Actually, for the retrofitted specimen with an effective plaster-frame connection (R2-OOP), the system "infill panel + retrofitting plaster" did not collapse out of its plane for an OOP displacement equal to the infill thickness. Nevertheless, to improve the ductility of this retrofitting system, particular care should be still addressed to the proper definition of the typology of the connectors and their spacing. To this aim, future desirable experimental tests should provide additional useful data. 


\section{CONCLUSIONS}

This paper presented an experimental work performed in the Laboratory of Earthquake and Structural Engineering of the Civil Engineering Department of the University of Porto in cooperation with the Department of Structures for Engineering and Architecture of the University of Naples Federico II, about the assessment of possible strengthening solutions designed to mitigate or avoid the out-of-plane collapse of hollow clay infills in existing $\mathrm{RC}$ buildings.

Three nominally identical full-scale one-bay-one-story RC frames were built and infilled with a thin masonry wall. The first specimen was representative of the "as-built" condition. The remaining two specimens were strengthened to improve the out-of-plane collapse vulnerability by means of two different strengthening techniques based on the application of high-ductility mortar plaster and fibre-reinforced polymer nets. All the tests consisted in the application of a semi-cyclic (loading-unloading-reloading) history of imposed displacements in the OOP direction by means of small pneumatic jacks through a uniform distributed load.

The experimental results have been showed in terms of OOP force-displacement responses, and damage evolution, and compared to each other. It was observed that the OOP strength capacity at OOP load at first cracking significantly increases (more than $+200 \%$ ) for the retrofitted specimens with respect to the as-built reference test, mainly due to the significant tensile strength of the adopted fibre-reinforced mortar. Similarly, the OOP secant stiffness significantly increases, as expected. On the contrary, the infill OOP displacement at peak load reduces in retrofitted infills by about $60 \%$. Nevertheless, note that, for the retrofitted specimen with an effective plaster-frame connection, the system "infill panel + retrofitting plaster" did not collapse out of its plane for an OOP displacement equal to the infill thickness.

In conclusion, certainly the presented data can be useful to provide a support towards the choice of the best strategies for future further investigations and applications. Additional experimental data will be certainly important to improve the OOP retrofitting system for masonry infills, with particular care to the plaster-frame connection system.

\section{ACKNOWLEDGEMENTS}

This work was developed under the support of AXA Research Fund Post-Doctoral Grant "Advanced nonlinear modelling and performance assessment of masonry infills in RC buildings under seismic loads: the way forward to design or retrofitting strategies and reduction of losses". This support is gratefully acknowledged.

The authors would like also to acknowledge to the Laboratory of Earthquake and Structural Engineering (LESE) technicians, Mr. Guilherme Nogueira and Mr. Nuno Pinto for their support in the experimental activity reported in this research work. Finally, the authors would like to specially acknowledge FASSA BORTOLO for the provision of the strengthening materials used in these experimental tests.

\section{REFERENCES}

[1] A. Furtado, H. Rodrigues, A. Arêde, H. Varum, Experimental evaluation of out-of-plane capacity of masonry infill walls. Engineering Structures, 111: p. 48-63, 2016.

[2] A. Furtado, H. Rodrigues, A. Arêde, H. Varum, Effect of the Panel Width Support and Columns Axial Load on the Infill Masonry Walls Out-Of-Plane Behavior. Journal of Earthquake Engineering, p. 1-29, 2018. 
[3] M. Di Domenico, P. Ricci, G.M. Verderame, Experimental Assessment of the Influence of Boundary Conditions on the Out-of-Plane Response of Unreinforced Masonry Infill Walls. Journal of Earthquake Engineering: p. 1-39, 2018.

[4] R. Angel, D.P. Abrams, D. Shapiro, J. Uzarski, M. Webster, Behaviour of reinforced concrete frames with masonry infills. University of Illinois Engineering Experiment Station. College of Engineering. University of Illinois at Urbana-Champaign, 1994.

[5] G. Guidi, F. da Porto, M. Benetta, N. Verlato and C. Modena (2013). Comportamento Sperimentale nel Piano e Fuori Piano di Tamponamenti in Muratura Armata e Rinforzata. XV Convegno Nazionale ANIDIS - "L'INGEGNERIA SISMICA IN ITALIA". Padova, Italy.

[6] L. Koutas, A. Pitytzogia, T. C. Triantafillou and S. N. Bousias (2014). Strengthening of Infilled Reinforced Concrete Frames with TRM: Study on the Development and Testing of Textile-Based Anchors. Journal of Composites for Construction 18(3): A4013015.

[7] F. Da Porto, G. Guidi, N. Verlato and C. Modena (2015). Effectiveness of plasters and textile reinforced mortars for strengthening clay masonry infill walls subjected to combined in-plane/out-of-plane actions / Wirksamkeit von Putz und textilbewehrtem Mörtel bei der Verstärkung von Ausfachungswänden aus Ziegelmauerwerk, die kombinierter Scheiben- und Plattenbeanspruchung ausgesetzt sind." Mauerwerk 19(5): 334-354.

[8] A. Martins, G. Vasconcelos, R. Fangueiro and F. Cunha (2015). Experimental assessment of an innovative strengthening material for brick masonry infills. Composites Part B: Engineering 80: 328-342.

[9] CEN (2005). Eurocode 8: Design of structures for earthquake resistance-part 1: general rules, seismic actions and rules for buildings.

[10] Decreto Ministeriale del 14/1/2008. Approvazione delle nuove norme tecniche per le costruzioni. G.U. n. 29 del 4/2/2008 (in Italian). 